\title{
A Exposição Universal de Viena de 1873 \\ e o Congresso Internacional sobre Patentes
}

\section{The Vienna World's Fair in 1873 and the International Patent Congress}

\author{
LEANDRO M. MALAVOTA \\ Instituto Brasileiro de Geografia e Estatística | IBGE \\ MÔNICA DE SOUZA NUNES MARTINS \\ Universidade Federal Rural do Rio de Janeiro | UFRRJ
}

\begin{abstract}
Resumo $\mathrm{O}$ artigo propõe uma reflexão sobre tecnologia e propriedade na segunda metade do Oitocentos, observando-se a construção de mecanismos de apropriação tecnológica em uma nova etapa do desenvolvimento capitalista. Durante a Exposição Universal de Viena, em 1873, foi promovido o Congresso Internacional sobre Patentes, primeiro evento de grande porte exclusivamente voltado à temática. Os debates ali produzidos tenderam a ratificar as funções cumpridas pelas patentes como ferramentas de proteção, recompensa e incentivo à inovação, defendendo-se a padronização dos conceitos, requisitos e procedimentos adotados de país a país e estimulando-se a adoção de uma legislação internacional unificada.
\end{abstract}

Palavras-chave exposições universais - desenvolvimento tecnológico - sistema de patentes - Congresso Internacional sobre Patentes.

\begin{abstract}
This paper reflects on technology and property in the late nineteenth century, observing the making of technology appropriation mechanisms in a new stage of capitalist development. During the Vienna World's Fair in 1873, the International Patent Congress was held, which was the first major event exclusively dedicated to the subject of industrial property rights. The debates tended to support the functions fulfilled by the patent system as a mechanism for protection, reward, and incentive to innovation, indicating the need to standardize concepts, rules, requirements and procedures adopted by different countries, as well as the adoption of an international patent law.
\end{abstract}

Keywords world fairs - technological development - patent system - International Patent Congress.

\section{Introdução ${ }^{1}$}

As exposições universais já foram objeto de estudos e análises efetuados por profissionais oriundos dos mais distintos ramos das ciências sociais. Espetáculos do progresso e de elogio à modernidade; $\underline{\underline{2}}$ loci de interação entre produção e consumo; $;$ celebrações da indústria, comércio, ciência e tecnologia; ${ }^{4}$ vitrines do exibicionismo burguês, $\underline{-5}$ templos do fetichismo da mercadoria; $;-\underline{6}$ fenômenos visuais que projetam ideologias e condensam visões de mundo; $;$ instrumentos didático-pedagógicos voltados à propagação de um sistema de valores e um projeto civilizatório; 
conhecimento e da cultura material do Ocidente; ${ }^{-\underline{9}}$ expressão e reificação de identidades e projetos nacionais. ${ }^{10}$ - Conforme podemos notar na obra de Nelson Sanjad, que de forma brilhante perscruta a literatura especializada e identifica suas mais importantes tendências, 11 quanto maior a multiplicidade de ângulos pelos quais as exposições universais sejam observadas, mais variadas serão as interpretações e definições sobre essas grandes feiras internacionais promovidas a partir de meados do século XIX, expressões indeléveis de seu tempo.

A despeito de constituir seara já bastante explorada, a extrema riqueza das temáticas que dela emanam não permite o seu esgotamento. Particularmente, as relações entre as exposições universais, a inovação e a propriedade tecnológica ainda oferecem inúmeras oportunidades de investigação. Decerto a literatura especializada já nos oferece algumas análises importantes. Christine Macleod observa o contexto das exposições universais para refletir sobre 0 papel do desenvolvimento técnico no processo de construção de uma identidade nacional na Inglaterra vitoriana, atrelando a ascensão do ideário liberal, o progresso técnico, a construção de uma representação heroica do inventor e as demandas por mudanças no arcabouço jurídico-institucional de proteção à atividade inventiva. ${ }^{12}$ Claire Pettitt, por sua vez, discute os desafios lançados a inventores e escritores em uma era marcada pela ampliação da reprodutibilidade de obras intelectuais. As exposições universais, em sua visão, evidenciaram a crescente mecanização da produção e da arte, estimulando os debates sobre a propriedade do trabalho intelectual. ${ }^{13}$ Já em uma abordagem mais propriamente econômica, Petra Moser se propõe a examinar os catálogos das Exposições Universais de Londres (1851) e Filadélfia (1876), em uma tentativa de identificar as relações entre os bens ali exibidos e os exclusivos patentários concedidos aos inventores. A autora conclui não haver evidências sólidas de que os direitos de propriedade industrial tenham constituído fatores fundamentais de indução ao desenvolvimento de grande parte das invenções ali reunidas, embora não se possa negligenciar a sua influência no direcionamento dos investimentos em pesquisa de país a país. $\underline{14}$

É digno de um registro à parte o trabalho de Yves Plasseraud e François Savignon. ${ }^{15}$ Em uma minuciosa pesquisa sobre as transformações ocorridas no sistema de patentes na segunda metade do século XIX - culminando com a assinatura, em 1883, do primeiro tratado internacional sobre a matéria, a Convenção da União de Paris para Proteção da Propriedade Industrial -, apontam o papel fulcral cumprido pelas exposições universais para a expansão do debate sobre os fundamentos e a regulação dos direitos do inventor. Argumentam que, por constituírem loci de apresentação e negociação de tecnologias de ponta, bem como de interação entre produtores e consumidores, também representavam espaços propícios à espionagem industrial e ao free-riding, este último geralmente alicerçado nas cópias indevidas. Este ambiente de insegurança teria despertado preocupações quanto aos melhores meios para se proteger legalmente a propriedade tecnológica, estimulando o debate entre industriais, inventores e especialistas no assunto (principalmente advogados, economistas e engenheiros). As grandes feiras, portanto, teriam criado o palco ideal para a internacionalização da questão da propriedade industrial, contribuindo para implantação de reformas no sistema.

A presente reflexão pretende prestar uma contribuição aos estudos sobre inovação, tecnologia e propriedade, tomando o Congresso Internacional sobre Patentes, realizado durante a Exposição Universal de Viena, de 1873, como objeto de análise. 0 artigo apresenta os resultados de uma pesquisa exploratória, fornecendo as bases para o desenvolvimento de uma investigação posterior sobre a inserção do Brasil no sistema internacional de propriedade industrial. Partilhando da percepção de Plasseraud e Savignon, entendemos que as exposições universais despertaram o interesse de diversos atores sociais sobre questões relacionadas às patentes de invenção - e em menor grau as concernentes às marcas de indústria e comércio, desenhos industriais e indicações geográficas. ${ }^{16}$ Além das demandas por maior proteção das tecnologias exibidas nas grandes feiras, compõem ainda esse quadro os interesses da grande empresa capitalista em mercados cada vez mais internacionalizados, sempre em prol da redução dos seus custos de transação. Destacamos ainda a tendência então em curso de multilaterização das relações internacionais, em um contexto de diversificação dos players na economia capitalista. As exposições universais, nesse sentido, constituíram espaços importantes para a construção de foros de discussão e deliberação sobre temas diversos da agenda econômica internacional, entre os quais a propriedade industrial auferiu considerável destaque. Quanto a este último aspecto, particularmente, consideramos a Exposição Universal de Viena e o Congresso Internacional sobre Patentes de 1873 como objetos passíveis de maior exploração, posto que ainda pouco estudados pela historiografia. 


\section{A Exposição Universal de Viena de 1873}

Nos anos 1870 o circuito das Exposições Universais deslocou-se pela primeira vez do eixo Londres-Paris, sedes dos eventos ocorridos nas duas décadas anteriores. Viena foi a cidade escolhida para receber a Grande Feira de 1873. Decerto a iniciativa do governo austro-húngaro vislumbrava evidentes objetivos políticos. Por um lado, propunha-se a criar uma oportunidade para o fortalecimento da imagem do Império no plano externo e atuar em favor da recuperação de seu prestígio, em um momento em que o país sofria consideráveis reveses em suas relações internacionais, incluindo perdas territoriais. No plano interno, as constantes pressões em um Estado multiétnico testavam o poder dos Habsburgo-Lorena, demandando esforços em prol da manutenção da unidade política. Nesse contexto, $025^{\circ}$ aniversário de coroação do imperador Franz Joseph constituía uma efeméride perfeita para a promoção de uma ampla mobilização em torno de uma causa nacional, dotando a exposição de uma carga simbólica particular. 0 evento pretendia representar a afirmação do Império austríaco, exaltando sua administração, sua indústria, seu progresso e sua cultura. Além disso, o governo pretendia apresentar ao mundo uma nova Viena, submetida ao mais ambicioso plano urbanístico até então já concebido na Europa, à exceção de Paris.

The old wall was leveled and turned into a boulevard of tremendous proportion, lined with grandiose buildings in an array of eclectic styles: neo-Gothic, Renaissance, baroque, and neoclassical. Predominantly financed by the newly rich bourgeoise, the Ring became a showpiece of capitalism. $\underline{17}$

Com amplo suporte governamental, a exposição foi organizada pela Lower Austrian Trade Association e presidida pelo arquiduque Regnier, ex-presidente do Conselho de Ministros (1861-1865) e ilustre membro da Casa Imperial. Ao todo, trinta países foram convidados a participar do evento. Entretanto, três dos mais importantes não foram oficialmente representados nem montaram, como nas feiras anteriores, os seus respectivos pavilhões nacionais: Grã-Bretanha,

França e Estados Unidos. É preciso destacar que a atuação dos governos no financiamento dos pavilhões nacionais era uma forma de apoiar e estimular os seus exibidores, garantindo a maior projeção possível dos gêneros nacionais. Não obstante a falta do fomento oficial dessas três grandes potências, seus produtores não estiveram ausentes. Os catálogos e as listas de medalhas e recompensas confirmam a larga participação de britânicos, franceses e norte-americanos em várias categorias, auferindo inclusive diversas premiações. ${ }^{18}$ Além disso, mesmo sem representação oficial, alguns governos enviaram observadores. Foi o caso, por exemplo, dos Estados Unidos, que enviaram uma comissão liderada por Robert $\mathrm{H}$. Thurston, responsável por um volumoso relatório, documento que posteriormente embasaria o processo de organização da Exposição Centenária da Filadélfia, em 1876. $\frac{19}{}$

Os pavilhões da Exposição Universal foram montados em um dos principais pontos da cidade de Viena, o famoso parque Prater, destacando-se entre as construções ali erigidas a que ficou conhecida como Rotunda. $\underline{20} 0$ evento, ocorrido entre $1^{\circ}$ de maio e 31 de outubro de 1873, foi marcado por tragédias e dificuldades iniciais. Naquele ano, um surto de cólera se alastrou por Viena causando a morte de aproximadamente duas mil pessoas, o que contribuiu para afastar os visitantes. Apenas em setembro, com o controle da epidemia, o fluxo de pessoas aumentou significativamente. Além disso, nos primeiros meses do evento, chuvas fortes e enchentes prejudicaram o acesso do público ao Prater e causaram estragos aos pavilhões. 11 No entanto, a despeito de tais contratempos, a Exposição de Viena, com suas edificações monumentais e seus apelos patrióticos, foi considerada um sucesso pelos organizadores, servindo em vários aspectos como referência para os promotores das exposições que a sucederam.

A Exposição de Viena deu-se em meio aos impactos da Segunda Revolução Industrial, em uma conjuntura de acelerado crescimento industrial e comercial na Europa. Ao mesmo tempo, constituiu precedente imediato de uma grande crise econômica no continente, caracterizada por uma queda generalizada dos preços e a redução da rentabilidade do capital. Conforme argumenta Eric Hobsbawm, tratava-se fundamentalmente de uma crise de lucratividade, não de produção. ${ }^{22} \mathrm{~A}$ Áustria seria um dos países mais duramente impactados pela depressão dos anos 1870 e o peso dos gastos envolvidos na Grande Feira de Viena acabou agravando a situação das finanças nacionais. Parte da dívida 
adquirida para financiar o evento não pôde ser honrada. Os efeitos econômicos e sociais decorrentes da crise europeia, contudo, não foram suficientes para desestimular a realização de outras feiras. Esses grandes eventos continuaram sendo utilizados como oportunidades de conclamação à unidade nacional, propagação de discursos nacionalistas e de reforço do capital político dos grupos no poder. $\underline{23}$

Outro aspecto a ser considerado na Grande Feira de Viena é o fato de ter constituído espaço privilegiado para a realização de eventos temáticos, geralmente congressos dedicados ao tratamento de matérias relevantes que perpassavam as relações econômicas. Desde meados do Oitocentos a atividade econômica se expandia em um ritmo acelerado, ampliando-se os câmbios estabelecidos entre as nações e elevando-se o número de países que se submetiam ao processo de industrialização. Na medida em que a grande empresa capitalista extrapolava as suas fronteiras nacionais e passava a atuar globalmente, surgiam pressões e iniciativas no sentido de se promover a padronização de normas e procedimentos que davam forma ao domínio econômico, tendo em vista a facilitação da atuação empresarial, garantia de segurança jurídica, redução de seus custos de transação e a aceleração do processo de circulação de mercadorias.

Consequência desse fenômeno foi o surgimento de organismos multilaterais de natureza técnico-administrativa, ensejando uma transformação significativa no sistema de relações internacionais. Se até então o grosso dos compromissos firmados entre países era regulado por acordos bilaterais ou por tratados envolvendo um número reduzido de potências - como no caso do Congresso de Viena (1815) e do Congresso de Paris (1857)는 -, no novo contexto os foros de natureza técnica ganhavam projeção e importância. As diversas conferências, convenções e organizações internacionais criadas na segunda metade do Oitocentos objetivavam enfrentar questões de ordem prática, tendo como escopo 0 tratamento de problemas técnicos ou regulatórios surgidos a partir da expansão capitalista e da internacionalização do comércio. Tratava-se de iniciativas visando à harmonização de métodos, trâmites e condutas em áreas que de alguma forma impactavam as atividades produtivas, tais como as comunicações, transportes, tarifas, moeda, cartografia, geodésia, educação, pesos e medidas, etc. Por constituírem espaços de convergência dos olhares e interesses dos mais distintos atores sociais, reunindo representantes de diversos países, as exposições universais foram transformadas em sedes, por excelência, de inúmeros desses eventos temáticos. Em seu seio foram construídas bases para a "discussão

substantiva de determinados temas de interesse momentâneo, abrindo assim o caminho a conferências diplomáticas e ao estabelecimento das primeiras uniões intergovernamentais". ${ }^{25}$ Em Viena, particularmente, foram realizados mais de uma dezena de congressos, envolvendo áreas diversas como a médica, agrícola, têxtil e de propriedade industrial. $\underline{26}$ Como proposto, nosso enfoque recairá sobre esta última.

\section{Breves considerações sobre a apropriação tecnológica e o sistema de patentes}

A patente de invenção pode ser entendida como um tipo de privilégio concedido pelo Estado que proporciona a seu detentor uma exclusividade temporária da exploração (produção e comercialização) de um novo produto ou processo de produção, impedindo que terceiros façam uso da invenção sem a sua autorização. De acordo com normas internacionais atualmente estabelecidas, o tempo mínimo para a validade de uma patente de invenção é de vinte anos,

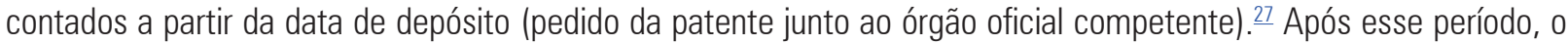
objeto tecnológico protegido cai em domínio público, podendo então ser livremente explorado por qualquer agente interessado. As distintas legislações nacionais que regulam a concessão de patentes adotam, embora com algumas nuances interpretativas de caso a caso, determinados requisitos para que uma dada invenção se torne patenteável: novidade - a invenção deve ser nova, ou seja, não pode ter sido realizada, executada ou explorada anteriormente; atividade inventiva - a invenção não pode ser uma decorrência óbvia do estado da técnica; e aplicabilidade industrial a invenção deve ser passível de utilização ou produção em qualquer tipo de indústria. Além disso, o inventor é obrigado a descrever pormenorizadamente a tecnologia por ele desenvolvida, tornando públicas as informações técnicas que 0 permitiram chegar à sua invenção. 
A concessão de exclusivos a inventores é uma prática conhecida na Europa desde o Baixo Medievo, ganhando impulso ao longo da Idade Moderna. Boa parte da historiografia, ao analisar as origens do sistema de patentes, privilegia as funções econômicas por ele cumpridas. Argumenta-se, em geral, que as cartas-patente constituíam ferramentas utilizadas por diversos monarcas europeus com o objetivo de atrair e fixar mão de obra estrangeira especializada, tendo em vista promover a diversificação da economia local, substituir importações e ampliar a sua base tributária. ${ }^{28}$ Sustenta-se ainda que, em estruturas produtivas alicerçadas na organização corporativa, os privilégios também funcionavam como licenças para produzir, permitindo que novos agentes contornassem as regulações e barreiras de entrada impostas pelas corporações de ofício. $\underline{29}^{29}$

Sem abandonar essas linhas interpretativas, ressaltamos que, além das funções econômicas apontadas, os exclusivos também cumpriam um importante papel político. Como qualquer outro tipo de mercê, as patentes permitiam a construção de relações de clientela e alianças entre a autoridade concessora e grupos sociais subordinados, proporcionando a produtores específicos meios para 0 alcance de benefícios econômicos privados. $\stackrel{30}{0}$ privilégio patentário, portanto, também funcionava como uma ferramenta para o engendramento de laços de dependência e lealdade entre o beneficiado (inventor ou introdutor) e o benfeitor (o monarca ou poder constituído diverso), refletindo e reproduzindo a lógica de organização e funcionamento da sociedade estamental.

A partir do último quartel do Setecentos, contudo, as funções e a natureza do sistema de patentes se redefinem, refletindo as profundas transformações em curso na Europa, evidenciadas nas mais distintas dimensões da experiência social. Na Grã-Bretanha as mudanças se apresentaram inicialmente na jurisprudência, passando os tribunais a impor paulatinamente novos critérios e exigências para a concessão e vigência dos exclusivos, entre os quais a detalhada descrição da invenção combinada a uma adequada definição das reivindicações - specification. Na França revolucionária, a velha estrutura bourbônica de privilégios foi derrubada, promulgando-se uma nova legislação patentária em 7 de janeiro de 1791. A Constituição dos Estados Unidos da América, por sua vez, assegurou a proteção aos inventores e a reconheceu como uma das obrigações do Estado, tipificando a patente como instrumento de estímulo ao desenvolvimento da ciência e das artes,$\frac{31}{31}$ princípio logo ratificado com a promulgação do Patent Act de 1790. Já no irromper do século XIX, o sistema de patentes se submetia a uma ressignificação funcional e conceitual em todo o Ocidente. À medida que valores e representações de natureza liberal emergiam e se consolidavam, os exclusivos deixavam de ser concebidos como mercês, graças régias concedidas como recompensa por serviços prestados ou por manifesto interesse do monarca, e se transformavam em um direito de propriedade regulado por lei. ${ }^{32}$

Se os impactos da Revolução Industrial convertiam a patente de mercê em propriedade, seu aprofundamento também provocaria novos efeitos transformadores. A segunda metade do século XIX inaugurou uma nova fase do processo de desenvolvimento industrial, baseada na expansão da estrutura capitalista de produção, da intensificação dos câmbios internacionais e de uma nítida quebra de paradigma tecnológico. A emergência de um conjunto de inovações radicais - especialmente na indústria pesada, nas comunicações e nos transportes - permitiu a dinamização e a complexificação das atividades econômicas, ganhos progressivos de escala e a redução de custos de produção. Enquanto a industrialização atingia um número cada vez maior de países, os padrões organizacionais e operacionais da economia capitalista se tornavam mais complexos, observando-se, entre outros fenômenos, uma forte tendência à concentração do capital, rápido crescimento urbano, a expansão do setor terciário e o desenvolvimento do mercado de capitais. ${ }^{3} \underline{3}$

A emergência de todo um conjunto de novos bens, processos e setores industriais serviu como alicerce ao já mencionado processo de expansão quantitativa e qualitativa da produção, proporcionando ganhos significativos de eficiência e produtividade. Constroem-se nesse ambiente novas relações entre mercado, ciência e tecnologia. Ao contrário do ocorrido no alvorecer do processo de industrialização - fase em que os principais avanços técnicos se basearam, principalmente, no conhecimento empírico progressivamente acumulado -, na segunda metade do

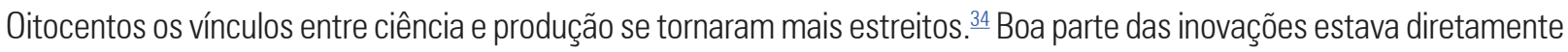
relacionada aos avanços recentes do conhecimento científico, particularmente nos campos da física e da química $\frac{35}{.}$ No núcleo dessa nova economia em construção - e aqui nos referimos à Europa Ocidental e aos Estados Unidos - a pesquisa se profissionaliza, ganhando status social e mobilizando recursos cada vez mais volumosos. 
Contribuía ainda para a expansão capitalista verificada no período uma tendência à liberação da ação do setor privado na economia, amparada na redução de regulações, entraves e intervenções que incidiam sobre o comércio e a produção. Restrições típicas a estruturas profissionais corporativas, leis contra usura, controles burocráticos sobre a associação empresarial, enfim, um conjunto de mecanismos econômicos não capitalistas foi sendo paulatinamente abolido ou reformado, em um movimento que transpassava fronteiras..$^{36} \mathrm{~A}$ convicção nos benefícios generalizados proporcionados pelo livre comércio - isto é, a imediata associação entre liberalismo, progresso e civilização - suscitou ainda uma ampla queda de tarifas aduaneiras e a proliferação de acordos comerciais, contribuindo para a potencialização do processo de expansão dos câmbios internacionais. $\cdot \frac{37}{}$

No tocante especificamente à atividade inventiva, configurava-se nesse contexto um duplo movimento. Por um lado, a consolidação da tecnologia como fator de produção importante dentro de um sistema econômico cada vez mais complexo e internacionalizado provocou a disseminação do uso dos mecanismos de apropriação tecnológica, sendo a patente ratificada como ferramenta privilegiada da grande empresa capitalista na busca por vantagens competitivas. A construção de portfólios de patentes, isto é, um conjunto de ativos intangíveis que garantem à empresa um dado feixe de direitos de propriedade, passava a ser tomada como ação estratégica para disputa e controle de mercados entre as nações. Por outro lado, a ascensão do ideário liberal, com toda a sua condenação a estruturas monopólicas e aversão a práticas intervencionistas submetia o sistema patentário a uma profunda crítica.

Se inicialmente as insatisfações se concentravam nos excessos burocráticos e nos altos custos por vezes envolvidos na concessão de exclusivos, pouco a pouco elas se tornavam mais contundentes, formando-se na Europa um franco movimento de oposição ao sistema de patentes. Suas características variavam de país, propondo-se desde uma profunda revisão em sua estrutura de funcionamento até mesmo a sua abolição definitiva. ${ }^{38}$ Sobre tais críticas, os argumentos eram geralmente recorrentes: a identificação das patentes a monopólios, privando os mercados dos benefícios da livre concorrência; as barreiras por elas criadas ao acesso a bens e processos de produção socialmente relevantes; as restrições impostas à difusão do conhecimento; a obstrução aos aperfeiçoamentos, exceto quando desenvolvidos pelo próprio inventor; a natureza coletiva do processo de construção do conhecimento técnico, não cabendo sobre este a apropriação individual. $\frac{39}{}$ As contestações ao sistema alcançariam seu ápice ao final dos anos 1860, quando nos Países Baixos a legislação local de patentes, em vigor desde 1817, foi revogada, como consequência direta de pressões exercidas sobre os Estados Gerais, o parlamento bicameral local...

\section{A Exposição Universal de Viena e os debates sobre a propriedade industrial}

No terceiro quartel do Oitocentos o tema das patentes foi lançado ao centro dos debates internacionais e, conforme exposto, os antecedentes da Grande Feira de Viena contribuíram para o acirramento das controvérsias. Plasseraud e Savignon assinalam que cerca de dois anos antes industriais norte-americanos já demostravam certa apreensão com o evento, entendendo que as providências até então tomadas pelo país-sede para garantir a proteção das máquinas e equipamentos que lá seriam expostos mostravam-se insuficientes. As exposições universais refletiam e consolidavam a expansão das relações econômicas internacionais, reunindo periodicamente em um só lugar as maiores realizações industriais e tecnológicas das mais importantes nações do mundo. Como corolário, favoreciam a espionagem industrial e a contrafação - isto é, execução de cópias indevidas de artefatos tecnológicos. Nas edições anteriores, realizadas em Londres (1851 e 1862) e Paris (1855 e 1867), os governos locais mobilizaram-se no sentido de promover a proteção dos bens então expostos, promulgando leis excepcionais e de vigências temporárias. Até um ano antes da Feira de Viena, no entanto, nada apontava que o procedimento seria repetido. Além disso, havia uma forte desconfiança dos produtores norte-americanos em relação à legislação austro-húngara, considerada extremamente restritiva no tocante aos direitos dos inventores e discriminatória quanto a estrangeiros. Um artigo anônimo publicado na revista Scientific American, prestigiado semanário nova-iorquino especializado na área científico-tecnológica, ilustra bem a questão: 
Constructors and patentees who have introduced their inventions in European countries have suffered grievous illtreatment at the hands of the Austrian authorities, whose regulations on the subject of patents are, to say the least, not formed for the protection and reward of foreign talent and ingenuity. One most vexatious rule is that which invalidates a patent unless the article be manufactured in the realm, within 12 months from the date of issue. Now as patents are, in a measure, characterized by the locality in which they take rise, and are generally most economically worked in the country in which they originate, it is almost equivalent to prohibition to enact that the locomotive engines of Great Britain, the telegraph instruments of the United States, and the printed muslins of France shall be manufactured on Austrian soil within a year from securing the patent, and is a preposterous requirement, which ill comports with our liberal system of granting patents to their subject. $\stackrel{41}{1}$

Nas entidades de representação da classe empresarial, nos ambientes acadêmicos e também na imprensa teve início a difusão de uma orientação de boicote norte-americano ao evento. $\underline{\text { 2 }}$ Na esteira dessas reclamações, parte do empresariado alemão também expressou suas preocupações e acenou com a possibilidade de aderir à proposta. . $^{43}$ 0 acirramento dos ânimos foi logo notado por autoridades austro-húngaras, gerando iniciativas visando à dissuasão do movimento. Primeiramente, a promulgação de uma lei extraordinária, ao estilo dos diplomas anteriormente elaborados por França e Reino Unido, concedendo proteção às tecnologias expostas no Prater de Viena contra usos não autorizados. Indo além das leis anteriores, a proteção era também extensiva a marcas e desenhos industriais.44

Para além da questão envolvendo a proteção das invenções estrangeiras na Exposição Universal, o governo austro-húngaro percebia nas ameaças de boicote uma forma de pressão sobre o país por mudanças mais duradouras e substanciais em sua legislação. De fato, a adoção de uma lei restritiva enquadrava-se em uma estratégia de política industrial, baseada na facilitação da reprodução de tecnologias desenvolvidas no exterior e na obrigatoriedade da exploração local dos objetos patenteados, de forma a impedir que o mercado interno se tornasse refém da importação de bens tecnologicamente complexos.

A Áustria-Hungria vinha sendo recorrentemente cobrada por alguns de seus principais parceiros comerciais a rever os seus padrões de proteção. Até então, os instrumentos preferenciais geralmente utilizados para regulação das relações econômicas entre diferentes nações eram os acordos bilaterais, terreno em que nem sempre o poder de barganha das partes envolvidas mostrava-se equilibrado. Talvez pensando em evitar negociações onde sua posição se mostrasse mais frágil, o Império Austro-Húngaro deu um passo além do esperado. Aproveitando-se do momento em que 0 tema da proteção patentária estava em alta, propôs a realização, em meio aos trabalhos da Exposição Universal de Viena, de um grande congresso internacional voltado ao tratamento da questão dos direitos do inventor. A estratégia mostrava-se perspicaz: por um lado, arrefecia os ânimos de norte-americanos e alemães, esvaziando as propostas de boicote, na medida em que se propunha a colocar em discussão uma possível reforma do direito patentário; por outro, direcionava essa discussão a um foro multilateral, ainda que não oficial, envolvendo nos debates questões e interesses que atingiam um número maior de nações e, com isso, diluindo as pressões que certamente lhe seriam impostas em tratativas bilaterais.

0 Congresso Internacional sobre Patentes, realizado de 4 a 8 de agosto no Pavilhão do Júri - um dos espaços mais nobres da Exposição de Viena - foi o primeiro grande evento a reunir especialistas de diversos países para debater o tema, bem como questões envolvendo a sua regulamentação. Constituiu uma iniciativa de natureza privada, sem a intervenção direta de instâncias governamentais, embora alguns Estados nacionais tenham sido convidados a enviar representantes oficiais. Seguindo proposta do Comitê Preparatório do congresso, liderado pelos alemães Carl Pieper e Carl Wilhelm Siemens, ${ }^{45}$ foram convidados industriais, inventores, engenheiros, advogados, economistas e acadêmicos em geral diretamente interessados na matéria..$\underline{46}$ Ficou igualmente sob a responsabilidade do comitê a prévia seleção de questões a serem discutidas nas sessões do evento. Tal trabalho ensejou a elaboração de cinco resoluções preliminares, que deveriam servir como objetos de avaliação, debate e deliberação pelos participantes do congresso.

Considerando o momento histórico em que o congresso se realizava, marcado pela emergência de um movimento político em prol da abolição do sistema de patentes, o evento revestiu-se de um espírito de resistência, e a defesa do 
sistema patentário apresentou-se como bandeira principal a ser hasteada desde a elaboração do programa. Decerto a necessidade de reformas era reconhecida, mas as propostas voltavam-se ao aprimoramento e fortalecimento da estrutura de proteção baseada nos exclusivos, não na refutação de sua legitimidade enquanto ferramenta de incentivo à atividade inventiva. As iniciativas, portanto, tencionavam privilegiar o aprofundamento da lógica da apropriação tecnológica e a sua universalização. Não apenas rechaçar qualquer iniciativa antipatentes, mas expandir o sistema internacionalmente, alicerçando-o em padrões, normas, práticas e procedimentos uniformes.

Desde as discussões preliminares mostrou-se claro que a harmonização legislativa era uma das principais demandas dos segmentos industriais ali representados. À medida que a economia capitalista se expandia e os mercados se internacionalizavam, as empresas de grande porte passavam a atuar com cada vez mais frequência além de suas fronteiras nacionais. Conforme já mencionado, a construção do conceito moderno de patente, concebida como propriedade privada do inventor (ainda que temporária) deu-se progressivamente a partir de fins do Setecentos, consolidando-se em todo o Ocidente ao longo da primeira metade do Oitocentos. Contudo, as legislações nacionais foram elaboradas em diferentes contextos e com objetivos diversos, refletindo as estratégias e interesses dos governos e das classes dominantes de cada país. Logo, ao fim do terceiro quartel do século XIX observava-se uma gritante disparidade entre as legislações, envolvendo conceitos, exigências, prazos, taxas e obrigações para concessão e vigência dos exclusivos. Para 0 grande empresariado que agora atuava em diferentes mercados, tais disparidades provocavam elevação de custos de transação e entraves à boa governança de seus portfólios de patentes. Além disso, havia grande insatisfação quanto ao tratamento diferenciado oferecido a estrangeiros em alguns países, colocando-os em posição desvantajosa vis-à-vis os produtores locais. A adoção de um tratamento jurídico igualitário para todos os usuários do sistema de patentes destacava-se entre as reivindicações do grande empresariado.

Um texto que compunha o programa do evento - assinado pelo arquiduque Regnier, presidente da Comissão Imperial Organizadora da Exposição Universal, e pelo barão de Schwarz-Senborn, ${ }^{47}$ diretor-geral da Exposição Universal - alertava que, perante a hostilidade que os mais exaltados defensores do livre-cambismo dispensavam ao sistema de patentes, era provável que este tivesse seus dias contados, a menos que se fizessem intervenções em sua estrutura, especialmente a padronização de conceitos, normas e procedimentos. . $^{48}$ A exortação ia ao encontro de uma percepção que parecia imperar entre os participantes do congresso, qual fosse, de que o sistema de patentes só poderia funcionar de maneira eficiente sob um modelo uniforme, aplicável a todos os países.

Os dois mais ativos membros do Comitê Preparatório, Carl Wilhelm Siemens e Carl Pieper, assumiram respectivamente a presidência e a secretaria-geral do congresso. Ao austríaco barão de Schwarz-Senborn foi atribuído o título de presidente honorário do evento. Iniciados os trabalhos sob a presidência de Carl Siemens, cerca de 150 especialistas tomaram assento no Pavilhão do Júri. Como em sua maioria partilhavam de uma visão laudatória acerca do direito patentário - na mesma linha do Comitê Preparatório -, poucas foram as controvérsias.

0 desenrolar do evento seguia a ordem das resoluções pré-estabelecidas, sendo as mesmas debatidas e votadas ponto a ponto. A primeira resolução era composta por sete itens, todos envolvendo a natureza do sistema de patentes e argumentos voltados à sua legitimação: 1) o senso de direito dos povos civilizados demanda a proteção legal do trabalho intelectual; 2) a patente constitui o meio mais prático, rápido e eficiente de se oferecer à sociedade novos bens e métodos de produção; 3) a proteção proporciona justa remuneração ao trabalho do inventor e incentivo à atividade inventiva, além de fomentar investimentos em pesquisa e desenvolvimento de novos produtos; 4) a patente promove a disseminação de informação tecnológica, facilita o acesso do público a novos bens e reduz o sacrifício de tempo e recursos para 0 alcance de progressos técnicos; 5) a patente inibe o segredo de fábrica; 6) a ausência de proteção patentária em um país provoca a evasão de mentes criativas e profissionais hábeis; 7) a experiência demonstra que todo titular de patente tem interesse de explorá-la o mais prontamente possível. $\underline{49}$

Percebe-se nitidamente que os itens elencados na primeira resolução constituíam uma resposta ao movimento abolicionista, a refutação das principais críticas que repercutiam na imprensa e nos principais círculos políticos e intelectuais europeus. Na base desse conjunto de proposições, uma premissa fundamental: 0 apartamento entre patentes 
e monopólios. Se as patentes incidiam sobre invenções, isto é, produtos e processos novos, elas não privavam a sociedade de nenhum bem já disponível no mercado, nada que fosse de domínio público. Seguindo essa concepção, ao contrário do que pregavam muitos abolicionistas, a sociedade não era prejudicada pelos exclusivos temporários; na verdade, era beneficiada, uma vez que oferecia aos indivíduos estímulos econômicos para o desenvolvimento de novos inventos, impedindo a estagnação tecnológica.

As proposições da primeira resolução foram aprovadas praticamente sem modificações. Alguns participantes chegaram a discursar defendendo a superioridade de mecanismos alternativos de proteção à atividade inventiva, como a distribuição de subsídios pecuniários aos inventores, a título de prêmios, por meio de fundos estatais ou privados..$^{50}$ Também a ideia de que as patentes eram incompatíveis com os princípios do livre-comércio e deletérias ao interesse coletivo foi defendida durante os debates. Porém, dada a composição da plateia, tais vozes mostravam-se dissonantes. A apologia do sistema de patentes foi muito bem construída por grandes expoentes dos campos produtivo e científico, encontrando pouca oposição em um auditório receptivo. Os argumentos contrários eram rechaçados ponto a ponto, com franco apoio da maioria dos presentes.. .11

Uma vez justificados e legitimados os fundamentos conceituais do sistema de patentes, passou-se então a discutir as regras do jogo. A segunda resolução concentrou-se nos aspectos regulatórios e procedimentais, sempre tendo em vista a sua padronização. Mais extensa do que a anterior, abrangia em resumo as seguintes propostas: 0 direcionamento dos exclusivos unicamente aos verdadeiros inventores ou seus representantes; a proibição de tratamento jurídico diferenciado a estrangeiros; a recomendação de adoção do exame prévio; estabelecimento de prazo mínimo para a validade de uma patente; obrigatoriedade do disclosure; $\underline{\underline{52}}$ moderação das taxas e demais custos envolvidos no patenteamento; adoção de mecanismos de salvaguarda contra abusos dos direitos de propriedade, tendo em vista 0 atendimento do interesse público; a flexibilização da exploração local obrigatória.

Defendia-se, a princípio, que tais proposições compusessem o cerne de uma legislação internacional de patentes, que deveria ser adotada por todos os países. Em relação aos itens supracitados, dois particularmente provocaram maiores controvérsias. Primeiramente, a questão do uso não autorizado das invenções patenteadas, em caso de interesse público. Ainda que a resolução defendesse uma justa compensação aos inventores nesses casos, os defensores da tese que identifica a propriedade sobre o trabalho intelectual como um direito natural do indivíduo a consideravam inaceitável e conflitante com o espírito da primeira resolução. Plasseraud e Savignon afirmam que tal posição, contrária a intervenções do Estado sobre o direito de propriedade, era muito comum entre os norte-americanos, enquanto os britânicos, por sua vez, eram os maiores defensores da previsão de mecanismos como a caducidade e a licença compulsória. $\underline{53}$ Exemplo da posição britânica pode ser encontrado nas intervenções de Thomas Webster, conselheiro de Sua Majestade e delegado do país no congresso, identificando a propriedade industrial como um direito positivo (e não um direito natural), sendo ao Estado facultado o exercício de qualquer intervenção em atendimento ao interesse público. ${ }^{54} \mathrm{~A}$ despeito da polêmica, a proposição foi aprovada, ainda que por maioria menos expressiva do que a notada nas demais. Já um segundo ponto controverso envolveu a questão da exploração local obrigatória. Ao ser lançada à discussão, a maior parte dos presentes ratificou a condenação a esse tipo de exigência, o que significava um desafio a países que utilizavam este mecanismo como ferramenta de política industrial (estímulo à instalação de fábricas em território nacional e proteção contra gêneros importados), como os casos da França e da Áustria-Hungria.

0 congresso deliberou ainda outras três resoluções, estas mais sucintas e restritas. Uma delas consistia em uma exortação aos governos a se engajarem no debate sobre a proteção patentária, dando início a negociações visando a uma ampla reforma jurídica, essa voltada à redução das disparidades observadas de país a país e da construção de mecanismos que garantissem a proteção internacional dos inventores. Já as demais tratavam de aspectos formais e administrativos relacionados ao próprio congresso, transformando o Comitê Preparatório em uma instância executiva permanente, com a missão de garantir a aplicação dos princípios e recomendações consagrados nas resoluções e dar continuidade dos debates sobre o tema, tanto pela agregação de novos interlocutores quanto pela realização de outros eventos afins.

Os desdobramentos do congresso foram imediatos. Um efeito relevante foi a formação, por ação do recém-criado Comitê Executivo, de comitês nacionais responsáveis por mobilizar industriais e inventores em diferentes países, inserindo-os 
nas discussões internacionais e contribuindo para a organização de seus interesses. Outro fato a ser apontado foi a criação, ainda em 1873, da então chamada Association for the Reform and Codification of Law of Nations (depois chamada International Law Association, ILA), em cujo âmbito o debate sobre patentes iniciado em Viena teve continuidade. A instituição resolveu adotar as resoluções daquele congresso como base para seus trabalhos, dando início a um projeto voltado à elaboração do texto para uma lei internacional. .5 Todas essas iniciativas estimularam a realização de um novo evento temático de grande porte, como aprofundamento dos debates ocorridos no Prater. A oportunidade foi aberta em 1878, por ocasião da realização de mais uma Exposição Universal em Paris.

Cabe uma breve observação acerca do posicionamento da França diante do debate internacional em curso. Embora produtores e inventores franceses tenham comparecido em peso à Exposição Universal de Viena, não há registros de sua presença no Congresso Internacional de Patentes. A despeito do convite efetuado pelo Comitê Preparatório, o país não enviou nenhum representante ou observador oficial. Na lista geral dos participantes também não identificamos nenhum francês ${ }^{\frac{56}{6}}$ embora não seja impossível que eventualmente algum interessado tenha se misturado à plateia.

A percepção partilhada quatro anos depois por Charles Thirion, engenheiro civil e um dos maiores expoentes do campo da propriedade industrial na França, era de que o país havia demonstrado claro desinteresse pelo evento de Viena e, com isso, perdido grande oportunidade para se inserir no debate internacional e influenciá-lo. ${ }^{57}$ Galvez-Behar, por sua vez, afirma que o evento não passou despercebido na França, sem, no entanto, apontar motivos para a inexistência de representantes daquele país. $\stackrel{58}{0}$ autor argumenta somente que a ausência francesa no evento permitiu que as resoluções adotadas se mostrassem conflitantes com os princípios e regras da legislação nacional, como a recomendação do exame prévio, a defesa do mecanismo da licença compulsória e a não obrigatoriedade da exploração local obrigatória. No que concerne às discussões travadas em 1873, define a França como um ator marginal.

Considerando o contexto político e econômico no qual a França se inseria, observamos que o país sofrera um doloroso revés na recém-encerrada Guerra Franco-Prussiana (1870-1871), e a Terceira República, iniciada no bojo do conflito, então enfrentava sérios desafios econômicos. A volumosa indenização paga à Prússia - cuja aliança com os demais Estados alemães saíra vitoriosa do conflito, impondo à França inclusive perdas territoriais - e as duras medidas visando à estabilização interna não eram propriamente fatores que contribuíam para a priorização do debate sobre os direitos dos inventores naquele momento. Talvez esses fatos ajudem a explicar a ausência francesa no evento. Contudo, se levarmos em conta que Thirion era um contumaz crítico da legislação francesa de patentes, ${ }^{59}$ por ele considerada como ultrapassada, incompleta e inadequada às necessidades da indústria e do comércio ao seu tempo, talvez possamos compreender sua frustração a partir de outro ângulo. Relembremos que o principal objetivo do congresso - e isso ficou evidenciado desde os trabalhos da Comissão Preparatória e a elaboração das resoluções preliminares - era a proposição de uma unificação legislativa em matéria de patentes. Entretanto, uma futura legislação internacional, conforme concebida pela maioria dos grupos de interesse ali representados, passava pela refutação de práticas de defesa de mercado ou de favorecimento de produtores locais em detrimento de concorrentes estrangeiros. E eram justamente mecanismos de tal tipo que alicerçavam o sistema de patentes francês. Logo, e aqui tomamos a afirmação como uma hipótese, é possível que se tenha configurado um boicote velado dos franceses ao Congresso Internacional realizado em Viena, por motivos diametralmente opostos ao boicote abortado de norte-americanos e alemães à Exposição Universal. Estes pressionavam pela formulação de uma legislação internacional dentro dos padrões adotados em seus próprios modelos jurídicos. Já os franceses resistiam a adaptar o seu sistema patentário aos moldes que as outras potências propunham.

Em um novo contexto, em meio aos preparativos da Exposição Universal de 1878, Thirion saudava a mudança de posicionamento do governo e do setor privado na França, que agora se mostravam dispostos a dar continuidade aos debates iniciados em Viena, atendendo aos apelos de especialistas, como ele, no tema da propriedade industrial. Elogiava também a promoção da tradução para o francês do relatório produzido pelo delegado britânico no Congresso Internacional de Viena, o reconhecido jurisconsulto Thomas Webster, documento que em sua opinião deveria ser tomado como base para a inserção de seus compatriotas nos debates. Mas ao contrário do evento anterior - que embora apoiado pelo governo austro-húngaro não contou com uma participação destacada de seus representantes -, desta feita 
diversas autoridades, incluindo ministros, diplomatas e parlamentares, empenharam-se pessoalmente na organização e promoção dos trabalhos. 0 novo encontro proposto na Exposição Universal de 1878 assumiria proporções muito maiores do que o realizado em 1873, mantendo a sua natureza privada, porém com uma participação oficial mais contundente, não apenas de franceses, mas de delegados de vários outros países. Compreendemos que essa transformação nas características e dimensões do foro de discussão - que desta vez contou com cerca de quinhentos participantes - não se deu ao acaso. Talvez ao perceber a tendência inaugurada em Viena e os caminhos que as discussões pareciam tomar, o governo francês, juntamente com diversos segmentos empresariais e acadêmicos, tenha decidido se integrar ao movimento, no intuito de preservar seus mais evidentes interesses. E pelo que as fontes disponíveis nos permitem observar,, 60 a entrada da França nesse cenário, com todo o seu peso político e econômico, provocou impactos significativos sobre o desenrolar das tratativas.

Os debates e negociações iniciados em 1873 chegariam finalmente a um desfecho dez anos depois, com a ratificação da Convenção da União de Paris para a Proteção da Propriedade Industrial (CUP), primeiro tratado internacional sobre patentes, marcas, desenhos industriais e indicações geográficas. Mas a legislação internacional unificada, pilar principal das discussões, nunca foi alcançada. 0 sistema internacional de propriedade industrial criado a partir de 1883 baseou-se na sobreposição de sistemas nacionais ancorados em padrões mínimos de proteção, não em uma lei única aplicável a todos os países. A influência exercida pela entrada da França no processo de negociações, nesse aspecto, parece inequívoca. Outro fato que não podemos deixar de citar é que ao grupo de 14 países que aderiram

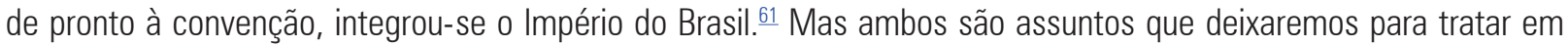
outras oportunidades. A história da propriedade industrial se apresenta como uma seara extremamente fértil e atrativa a explorações futuras.

\section{Considerações finais}

0 Congresso Internacional sobre Patentes, organizado durante a Exposição de Viena de 1873, constituiu oportunidade para a organização e propagação de um discurso de defesa do sistema de patentes, em um momento em que sua legitimidade era contestada em toda a Europa. Nesse sentido, os debates e resoluções ali produzidos tenderam a ratificar os exclusivos temporários como os mais eficientes mecanismos de proteção, recompensa e estímulo à atividade inventiva, considerados fundamentais ao progresso da indústria e ao desenvolvimento tecnológico. Além disso, os trabalhos também apontaram para a necessidade de padronização dos conceitos, regras e procedimentos adotados pelas distintas leis nacionais de patentes, estimulando-se iniciativas em prol da adoção de uma legislação internacional unificada.

Decerto o evento aqui estudado não configurou o fato mais importante no processo de regulamentação internacional da propriedade industrial. Nem mesmo todas as suas resoluções mostraram-se executáveis na prática, conforme evidenciado no desenrolar das negociações. Consideramos, entretanto, inegável a sua importância. Diante da força e dimensão que o movimento antipatentes apresentava naquele momento e das vitórias que vinha alcançando, o Congresso Internacional realizado em Viena representou um ponto de inflexão naquela disputa, fazendo o pêndulo se mover em outro sentido. Esse foi o momento que marcou a definitiva organização dos interesses pró-patentes e a tomada de ações políticas concretas, com estratégias e objetivos bem definidos. Foi também a partir desse evento, tanto em consequência das ações e decisões nele tomadas quanto por efeito da crise econômica que começava a assolar a Europa - fragilizando o ideário livre-cambista - que teve início a debacle do abolicionismo e a inauguração de uma nova fase do sistema de patentes, caracterizada por sua internacionalização. Representou, enfim, um passo ainda inicial, porém decisivo, para a determinação das feições que o sistema internacional de patentes assume até os nossos dias.

Embora haja um volume razoável de estudos históricos sobre a temática da apropriação tecnológica e dos direitos do inventor, raras são as análises sobre o Congresso de Viena, geralmente só mencionados como preliminares 
do Acordo de Paris. Acreditamos que isto nos tenha servido como um importante fator motivador, impelindo-nos a procurar contribuir para o avanço das pesquisas sobre a história da propriedade intelectual. Indo além, pretendemos, se possível, lançar luzes sobre a participação brasileira na CUP, acreditando que a investigação ora desenvolvida também constitua um exercício importante para uma melhor compreensão acerca do processo de inserção e atuação do país nesse importante foro multilateral. Torcemos para que a iniciativa sirva como um chamamento aos pesquisadores interessados na matéria.

\section{Notas e referências bibliográficas}

Leandro Malavota é doutor em História pela Universidade Federal Fluminense (UFF), professor do Programa de Pós-graduação em Propriedade Intelectual e Inovação do Instituto Nacional da Propriedade Industrial (PPGP//NPI) e pesquisador associado ao INCT Proprietas.

Mônica Martins é doutora em História Social pela Universidade Federal do Rio de Janeiro (UFRJ), professora do Departamento de História da Universidade Federal Rural do Rio de Janeiro (UFRRJ), vinculada aos Programas de Pós-graduação em História (PPHR/UFRRJ) e Patrimônio, Cultura e Sociedade (PPGPACS/UFRRJ), pesquisadora associada ao INCT Proprietas e coordenadora do Núcleo de Pesquisa Propriedade e suas Múltiplas Dimensões (Nupep).

10 presente artigo é parte do projeto de pesquisa intitulado "As Exposições Universais sob o prisma da inovação tecnológica: 0 Rio de Janeiro como lócus da modernidade entre os séculos XIX e XX", coordenado pela Prof. ${ }^{a}$ Dr. ${ }^{\text {a }}$ Mônica de Souza Nunes Martins e desenvolvido no âmbito do Nupep. Os autores agradecem a todos os colegas que contribuíram para o desenvolvimento deste trabalho.

2 PESAVENTO, Sandra. Exposições Universais: espetáculos da modernidade no século XIX. São Paulo: Hucitec, 1997, p. 43-44.

3 BOUDIN, Philippe; CHANUT, Christian-Philippe. Histoire française des foires et des expositions universelles. Paris: Nesle, 1980. p. 55-73.

4 SANJAD Nelson; CASTRO, Anna Raquel M. Comércio, política e ciência nas exposições internacionais: o Brasil em Turim, 1911. Parte 1. Varia Historia. Belo Horizonte, v. 31, n. 57, p. 819-861, set/dez 2015.

5 HARDMANN, Francisco Foot. Trem fantasma: a modernidade na selva. São Paulo: Companhia das Letras, 1988. p. 49-65.

6 BENJAMIN, Walter. Passagens. Belo Horizonte: Editora da UFMG, 2009. p. 35-43.

7 BARBUY, Heloísa. A exposição universal de 1889 em Paris: visão e representação na sociedade industrial. São Paulo: Loyola, 1999. p. 49-51.

8 RYDELL, Robert W.; FINDLING, John E.; PELLE, Kimberly D. Fair America: world's fairs in the United States. Washington: Smithsonian Institution, 2000

9 SCHROEDER-GUDEHUS, Brigitte; RASMUSEN, Anne. Les fastes du progress: le guides des expositions universelles, 1851-1992. Paris: Flamarion, 1992. p. 24.

10 TENORIO-TRILLO, Mauricio. Mexico at the World's Fairs: crafting a modern nation. Berkeley: Berkeley University Press, 1996. p. 15-27.

11 SANJAD, Nelson. Exposições internacionais: uma abordagem historiográfica a partir da América Latina. História, Ciências, Saúde - Manguinhos. Rio de Janeiro, v. 24, n. 3, p. 785-826, 2017

12 MACLEOD, Christine. Heroes of invention: technology, liberalism and British identity, 1750-1914. Cambridge: Cambridge Univesity Press, 2007, p. $212-279$.

13 PETTITT, Clare. Patent inventions: intellectual property and the Victorian Novel. New York: Oxford University Press, 2004. p. 84-148.

14 MOSER. Petra. How do patent laws influence innovation? Evidence from nineteenth-century World Fairs. American Economic Review, v. 95, n. 4, p. 121436, 2005.

15 PLASSERAUD, Yves; SAVIGNON, François. Paris, 1883: genèse du droit unioniste des brevets. Paris: Litec, 1983.

$16 \quad$ Idem, p. 120-122

17 SIRK, Leila G. Vienna 1873, In: FINDLING, John E.; PELLE, Kimberly D. (eds.). Historical Dictionary of World's Fairs and Expositions, 1851-1988. New York: Greenwood, 1990. p. 48-54, [p. 48].

18 COMMISSARIAT GENERAL DE FRANCE. Exposition International de Vienne, 1873: liste des récompenses décernées aux exposants français par le jury international. Paris: Imprimerie Nationale, 1874

19 SIRK, 1990, op. cit., p. 51.

20 Uma marca das exposições universais era a grandeza arquitetônica demonstrada em obras singulares construídas em cada um dos eventos, tendência inaugurada pelo Palácio de Cristal da Great Exhibition de 1851, em Londres. Em Viena, essa característica espetacular era notada na Rotunda, designação dada ao Palácio da Indústria, desenhado por Karl Hasenaur e projetado pelo engenheiro John Scott Russell. Esse prédio sediou várias exposições até ser destruído por um incêndio em 1937.

21 SIRK, 1990, op. cit., p. 49-53.

22 HOBSBAWM, Eric. A era dos impérios, 1875-1914. Rio de Janeiro: Paz e Terra, 1988. p. 58-9.

23 RYDELL, FINDLING, PELLE, 2000, op. cit, p. 19.

240 Congresso de Viena, de 1815, é considerado pela literatura especializada como o primeiro grande foro multilateral da modernidade, estabelecendo uma nova ordem política na Europa, conforme os interesses das potências vencedoras das Guerras Napoleônicas. Já o Congresso de Paris, de 1856, formalizou a paz na região do mar Negro após a conclusão da Guerra da Crimeia, estabelecendo um conjunto de convenções concernentes ao direito marítimo. 
ALMEIDA, Paulo R. Formação da diplomacia econômica no Brasil: as relações econômicas internacionais no Império. Brasília: Funag, 2017. p. 528. Grifos do autor.

26 THRUSTON, Robert H. Reports of the Commissioners of United States to the International Exhibition held at Vienna, 1873. V.1. Washington, DC: Government Printing Office, 1876. p. 80.

270 período mínimo de validade das patentes de invenção é hoje estabelecido pelo artigo 33 do Acordo sobre Aspectos de Propriedade Intelectual Relacionados ao Comércio (Trips), tratado firmado no âmbito da Organização Mundial do Comércio (OMC), em 1994.

28 MAY, Christopher; SELL, Susan. Intellectual property: a critical history. Boulder: Lynne Rienner, 2005. p. 43-74; DAVID, Paul. Intellectual property institutions and the panda's thumb: patents, copyrights and trade secrets in economic theory and history. In: WALLERNSTEIN, M., MOGEE, M., SCHOEN, R. (eds.). Global dimensions of intellectual property rights in science and technology. Washington, DC: National Academy Press, 1993. p. 19-61; MACLEOD, Christine. Inventing the Industrial Revolution: the English patent system (1660-1800). Cambridge: Cambridge University Press, 1988. p. 10-39.

29 CARVALHO, Nuno P. Estrutura dos sistemas de patentes e marcas: passado, presente e futuro. Rio de Janeiro: Lumen Juris, 2009, p. $198-275$.

30 MALAVOTA, Leandro M. A construção do sistema de patentes no Brasil: um olhar histórico. Rio de Janeiro: Lumen Juris, 2011. p. 6-11.

31 Conforme estabelecido na Constituição dos Estados Unidos, em seu artigo I, seção 8.

32 MALAVOTA, 2011, op. cit, p. 16-25.

33 LANDES, David. Prometeu desacorrentado: transformação tecnológica e desenvolvimento industrial na Europa ocidental de 1750 até os dias de hoje. Rio de Janeiro: Nova Fronteira, 1994. p. 201-38.

34 SZMRECSÁNYI, Tamás, Esboços de história econômica da ciência e da tecnologia. In: SOARES, Luiz Carlos (org.). Da Revolução Científica à Big-Business Science: cinco ensaios de história da ciência e da tecnologia. São Paulo: Hucitec; Niterói: EDUFF, 2001. p. 155-201; SOARES, Luiz Carlos. A filosofia natural e experimental na Inglaterra do século XVIII: um diálogo com a historiografia acerca da ideia de "ciência" na Era da Luze". Rio de Janeiro: 7 Letras, 2020.

35 Para efeitos deste trabalho, definiremos o conceito de inovação a partir de uma perspectiva restrita e unicamente tecnológica, tomando-se o termo como a introdução bem sucedida de novos bens (invenções) no mercado, a efetuação de aperfeiçoamentos em bens já existentes ou o desenvolvimento de novos métodos e técnicas de produção. Para uma definição mais abrangente, ver ORGANIZAÇÃO PARA A COOPERAÇÃO E DESENVOLVIMENTO ECONÔMICO (OCDE). Manual de Oslo: diretrizes para coleta e interpretação de dados sobre inovação. Brasília: OCDE/Finep, 2005.

36 HOBSBAWM, Eric. A era do capital, 1848-1875. Rio de Janeiro: Paz e Terra, 1996. p. 61-67.

37 CERRA, Ángel. La industrialización em Alemania, Estados Unidos y Rusia. In: BARBERO, María Inés et al. Industrialización y desarrollo: um acercamiento a los processos económicos contemporâneos. Buenos Aires: Biblos, 2004. p. 35-58.

38 COULTER, Moureen. Property in ideas: the patent question in Mid-Victorian England. Kirksville, M0: Thomas Jefferson Press, 1991. p. 75-101.

39 JANIS, Mark D. Patent Abolitionism. Berkeley Technology Law Journal, v. 17, n. 2, p. 899-952, 2002. [p. 922-948]

40 MACHLUP, Fritz, PENROSE, Edith. The patent controversy in the nineteenth century. The Journal of Economic History. New York, v. 10, n.1, p. 1-29, 1950. [p. 4-5].

41 THE GREAT Exhibition at Viena, 1873. Scientific American. New York, v. 25, n. 26, 23, p. 407, 23 Dec. 1871

42 LADAS, Stephen. Patents, trademarks, and related rights: national and international protection, v.1. Cambridge, MA: Harvard University Press, 1975. p. 59-60.

43 MAY; SELL, 2005, op. cit., p. 118-119.

44 GREAT BRITAIN Royal Comission for the Vienna Universal Exhibition of 1873. Reports on the Vienna Universal Exhibition of 1873, Part IV. London: G.E. Eire \& W. Spottiswoode, 1874. p. 337.

45 Carl Pieper era um engenheiro civil residente em Dresden, reconhecido especialista na área de propriedade industrial. Carl Wilhelm Siemens era engenheiro e grande expoente do empresariado industrial, nascido em Hannover e radicado na Inglaterra. Junto com seu irmão, Werner Siemens, foi fundador de um dos maiores conglomerados industriais da Europa.

46 GB Royal Comission, 1874, op. cit, p. 340-341.

47 Wilhelm von Schwarz-Senborn era economista, educador e diplomata, além de membro da Lower Austrian Trade Association. Foi conselheiro pessoal do imperador Franz Joseph e membro da delegação oficial austríaca nas Exposições Universais de 1855, 1862 e 1867.

48 WEBSTER, Thomas. Congrès International des brevets d'invention tenu a l'exposition universelle de Vienne en 1873. Paris: Marchal, Billard, 1877. p. 4.

49 GB Royal Comission, 1874, op. cit., p. 343-344.

$50 \quad$ Idem, p. 344-345.

$51 \quad$ Idem, p. 345-349.

52 Definimos o disclosure como a descrição minuciosa da invenção, revelando-se a informação técnica que permitiu ao inventor desenvolver a sua obra. A obrigatoriedade do disclosure, em tese, objetiva disponibilizar à sociedade conteúdos que permitam a qualquer pessoa minimamente entendida no assunto reproduzir a invenção, desde que dentro das permissões legais. 0 disclosure é de tal modo concebido como uma ferramenta de disseminação tecnológica.

53 PLASSERAUD; SAVIGNON, 1983, op cit., p 152. Grosso modo podemos definir a caducidade como o cancelamento da vigência de uma patente em função de sua não exploração. Já a licença compulsória pode ser definida como um mecanismo que autoriza o uso por terceiros de um objeto patenteado sem o consentimento do titular, ainda que este não perca seus direitos de propriedade e venha a ser ressarcido por esse uso.

54 GB Royal Comission, 1874, op. cit., p. 358-359.

55 GALVEZ-BEHAR, Gabriel. The 1883 Paris Convention and the imposible unification of industrial property. In: GOODAY, Gaerme; WILF. Steven (eds.). Patent cultures: diversity and harmonization in historical perspective. Cambridge: Cambridge University Press, 2020. p. 38-68 [p. 53].

56 WEBSTER, 1877, op. cit, p. 7-15.

57 THIRION, Charles. Avant-propos. In: WEBSTER, Thomas. Congrès International des brevets d'invention tenu a l'exposition universelle de Vienne en 1873. 
Paris: Marchal, Billard, 1877. p. II-IV.

58 GALVEZ-BEHAR, Gabriel. La République des inventeurs: propriété et organization de l'inovation en France, 1791-1922. Rennes: PUR, 2008. p. 157.

59 Lei de 5 de julho de 1844, que regulamentava a concessão e vigência de patentes de invenção na França, com emendas estabelecidas pela Lei de 31 de maio de 1856.

60 MINISTÈRE DE L'AGRICULTURE ET DU COMMERCE. Congrès International de la Proprieté Industrielle, Compte Rendues Stenograpriques. Paris : Imprimerie National, 1879. MINISTERE DES AFFAIRES ÉTRANGERES. Conférence Internationale pour la Protection de la Propriété Industrielle. Paris: Imprimerie National, 1880. BARBOSA, Antônio L.F. Patente: da licença compulsória ao uso sem autorização. In: Machado, M; MARTINS, W.; MARTINS, M. (orgs.). Propriedade em debate: modernização, recursos naturais e propriedade intelectual no Brasil. Rio de Janeiro: Autografia; Guarapuava: Ed. Unicentro, 2018. p. 111-126.

610 Brasil foi um dos 11 signatários originais da Convenção da União de Paris, juntamente com Bélgica, El Salvador, Espanha, França, Guatemala, Itália, Países Baixos, Portugal, Sérvia e Suíça. Em 1884, por ocasião da troca de ratificações entre os países que compunham a convenção, uniram-se a esse grupo Grã-Bretanha, Tunísia e Equador.

[Recebido em Setembro de 2020. Aceito para publicação em Março de 2021] 